\title{
Formulation and Evaluation of Natamycin Solid Dispersion Incorporated Ophthalmic Films
}

\author{
Lavanya Bhandari, Archana S Patil ${ }^{\star}$, Udaykumar Bolmal, Rajashree Masareddy, Panchaxari Dandagi
}

Department of Pharmaceutics, KLES College of Pharmacy, Belagavi, KLE Academy of Higher Education and Research, Belagavi, Karnataka, INDIA.

\begin{abstract}
Background: The aim of this study was to enhance the solubility of Natamycin, an antifungal agent used in fungal keratitis, through solid dispersion incorporated ophthalmic films with the purpose to avoid frequent dosing, enhance the period of retention, and sustaining release for better patient compliance. Materials and Methods: Firstly, solid dispersions were prepared by the solvent evaporation method and then, the best solid dispersion formulation was incorporated into films which were prepared by the solvent casting method using retarding polymers Ethyl cellulose, PVA and Chitosan. PEG-400 was used as a plasticizer. The films were evaluated for their thickness, surface $\mathrm{pH}$, drug content, weight uniformity, folding endurance, tensile strength, antimicrobial activity, in-vitro and ex-vivo permeation studies, and in-vitro antifungal studies. Results and Discussion: The films exhibited good mechanical properties with promising results and were in an acceptable range. The optimized formulation NF6 shows more drug release in in-vitro studies as compared to ex-vivo. This is due to the varying pore size of the cornea and disturbance of other tissues. An ocular irritation test revealed that the prepared formulation was non-irritant. Conclusion: Thus, the formulated ophthalmic film seems to be a promising formulation for the safe and effective delivery of Natamycin through the ocular route in the treatment of fungal keratitis.
\end{abstract}

Key words: Ophthalmic films, Natamycin, Ethyl cellulose, PVA, Chitosan.

\section{INTRODUCTION}

The Ocular Drug Delivery System was an advancement that came into existence in the past twenty years and combats over the utilization of the suspensions, eye drops, ointments, and other ocular drug delivery systems. ${ }^{1,2}$ Ocular route serves as a real benefit over the conventional dosage forms since the drainage of the drug from nasolacrimal path; non-corneal absorption gets and flushes out from the pre-corneal path without reaching the targeted site. The cornea is the main part through which light gets reflected onto the retina, making it a good site for rapid absorption and high bioavailability. ${ }^{3}$

Fungal keratitis, which can lead to blindness, is the leading cause of ocular morbidity. Fungi are responsible for over 62 percent of microbial keratitis in warm, tropical climates. Plant trauma is one of the predisposing causes of keratitis. ${ }^{4}$ Candida species, Fusarium species, and Aspergillus species are the most commonly detected fungal causes of keratitis. Antiviral, antifungal, and antibacterial treatments are given depending on the spread of infection. ${ }^{5}$ Polyene antibiotics (Amphoteric B, Natamycin (pimaricin), Nystain, and others) and Azoles (Imidazole: Clotrimazole, Ketoconazole, Miconazole, and others) are common tropical antifungals used for eye infections. ${ }^{6}$ Pathogenic fungi can be found in filamentous moulds or intracellular yeast, and they can infect animals or people. Chitin and polysaccharides, which function as a barrier to drug penetration, are used to make the fungal cell wall stiff. Fungi static is the responsibility of the
Submission Date: 17-06-2021; Revision Date: 18-08-2021; Accepted Date: 10-09-2021.

DOI: 10.5530/ijper.56.1.13 Correspondence: Dr. Archana S Patil, Assistant Professor, Department of Pharmaceutics, KLE College of Pharmacy, KLE Academy of Higher Education and Research, Belagavi, Karnataka-590010, INDIA.

E-mail: archupharma@gmail. com



www.ijper.org 
host. ${ }^{6,7}$ Natamycin is a BCS class -II drug which is now marketed as a 5 percent $\mathrm{w} / \mathrm{v}$ ophthalmic suspension. When used in the frontal portion of the eye, conventional formulations permeate through the cornea to the inner tissues of the eyes in a relatively small amount $(5 \%) .{ }^{8}$ Thus, to enhance bioavailability, the retention time of the drug on the administered site should be extended., ${ }^{9} 10$ To enhance the bioavailability of Natamycin, various systems have been developed by researchers, which include, niosomes, ${ }^{11}$ solid lipid nanoparticles, ${ }^{12,13}$ mixed micelles, ${ }^{14}$ nanosuspension, ${ }^{15}$ etc.

Ophthalmic films are polymer-based films that can be kept in the outer region of the eye for longer periods of time. These are made up of several grades of polymer that dissolve when exposed to physical stressors. They have numerous advantages over other conventional forms since they are biodegradable in nature, retain for a longer period of time at the site of action, and are less expensive, that leads to enhanced bioavailability and patient compliance. ${ }^{16}$

As a result, the primary goal of this study was to develop and evaluate a Natamycin ophthalmic film using a solid dispersion approach to improve solubility, increase drug retention time on the site, and improve bioavailability. As a retarding polymer, PVA, Chitosan, and ethyl cellulose were utilized.

\section{MATERIALS AND METHODS}

Natamycin IP was procured from Chihong biotechnology, china. Ethyl cellulose (M/s Colorcon Pvt. Ltd. Goa), Polyvinyl alcohol (Fisher scientific Mumbai), Chitosan (Sigma Aldrich, Mumbai) PEG 400 (MERCK Pvt. Ltd Mumbai), All other chemicals were procured from SD fine chemicals Mumbai.

\section{Methods}

\section{Solubility Analysis}

Natamycin solubility study was carried out in a metabolic shaker for $24 \mathrm{hr}$ at $37 \pm 2^{\circ} \mathrm{C}$. The solvents used were methanol, phosphate buffer $\mathrm{pH} 7.5$ and a mixture of ethanol: $6.8 \mathrm{pH}$ buffer (1:2). The drug content assay was performed by UV spectrophotometer (Shimadzu UV 1900 Pharmaspec, Japan) $\lambda_{\max } 303 \mathrm{~nm}$ after serial dilution within the Beer's range $(2-10 \mu \mathrm{g} / \mathrm{ml})$.

\section{Preparation of Solid Dispersions}

The solvent evaporation method was used to prepare the solid dispersion product. ${ }^{17}$ The drug and polymer complex were prepared by varying the drug: polymer ratio and concentration of polymers (HPMC K100M, HPMC K4M and PVA) as shown in Table 1. Natamycin

\begin{tabular}{|c|c|c|c|c|c|c|}
\hline 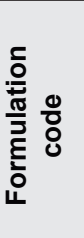 & 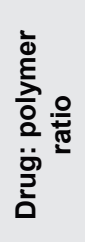 & 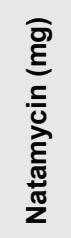 & 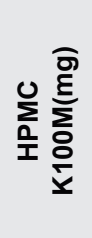 & 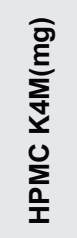 & 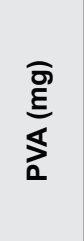 & 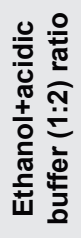 \\
\hline SD1 & 1:1 & 500 & 500 & - & - & 20 \\
\hline SD2 & 1:2 & 500 & 1000 & - & - & 20 \\
\hline SD3 & $1: 3$ & 500 & 1500 & - & - & 20 \\
\hline SD4 & $1: 1$ & 500 & - & 500 & - & 20 \\
\hline SD5 & $1: 2$ & 500 & - & 1000 & - & 20 \\
\hline SD6 & $1: 3$ & 500 & - & 1500 & - & 20 \\
\hline SD7 & 1:1 & 500 & - & - & 500 & 20 \\
\hline SD8 & $1: 2$ & 500 & - & - & 1000 & 20 \\
\hline SD9 & $1: 3$ & 500 & - & - & 1500 & 20 \\
\hline
\end{tabular}

and polymers were dissolved in ethanol: acidic buffer of $\mathrm{pH} 6.8$ (1:2 ratio) with the aid of a magnetic stirrer for $2 \mathrm{hr}$ at room temperature. The clear solvents were evaporated on water bath at $60^{\circ} \mathrm{C}$ for $3 \mathrm{hr}$. The dried mass was pulverized and passed through 60 mesh and stored in an air tight container.

\section{Evaluation of Solid Dispersions \\ Drug Content and In-vitro Dissolution Study}

With continuous stirring on a magnetic stirrer, the weighed quantity of solid dispersion was dissolved in $7.4 \mathrm{pH}$ phosphate buffer, and dilutions were made according to the beer's range. A UV spectrophotometer set at $303 \mathrm{~nm}$ was used to determine the drug content. In $900 \mathrm{ml}$ of $7.4 \mathrm{pH}$ phosphate buffer, an in-vitro dissolution analysis of solid dispersed product was conducted using a USP type II apparatus maintained at $37 \pm 0.5^{\circ} \mathrm{C}$ temperature with continuous stirring at $50 \mathrm{rpm}$. At predetermined intervals, $5 \mathrm{ml}$ of the samples were collected from the media and replaced with fresh dissolution medium in the same amount. The withdrawn samples were filtered via Whatman filter paper and quantified at $303 \mathrm{~nm}$ using a UV Spectrophotometer. ${ }^{18}$

\section{Formulation of Natamycin Solid Dispersions Incorporated Ophthalmic Films}

Six Natamycin ophthalmic films were prepared by using the solvent casting method. ${ }^{19}$ Chitosan, ethyl cellulose, and PVA polymers were used as retarding polymers along with casting solvents acetic acid + distilled water, chloroform, and distilled water respectively. PEG 400 was used as a plasticizer. The detailed compositions of 
Table 2: Composition of Natamycin Solid Dispersion Incorporated Ophthalmic Films.

\begin{tabular}{|c|c|c|c|c|c|c|}
\hline \multirow{2}{*}{ Ingredients } & \multicolumn{5}{|c|}{ Formulation Code } \\
\cline { 2 - 7 } & NF1 & NF2 & NF3 & NF4 & NF5 & NF6 \\
\hline $\begin{array}{c}\text { Natamycin } \\
\text { dispersion } \\
\text { equivalent } \\
\text { to1.44gms }\end{array}$ & 5.76 & 5.76 & 5.76 & 5.76 & 5.76 & 5.76 \\
\hline PVA(gms) & 0.2 & 0.3 & - & - & - & - \\
\hline $\begin{array}{c}\text { Ethyl Cellulose } \\
\text { (gms) }\end{array}$ & - & - & 0.25 & 0.3 & - & - \\
\hline $\begin{array}{c}\text { Chitosan (gms) } \\
\text { Chloroform (ml) }\end{array}$ & - & - & - & - & 0.2 & 0.25 \\
\hline $\begin{array}{c}\text { Distilled Water } \\
\text { (ml) }\end{array}$ & 15 & 15 & - & - & - & - \\
\hline $\begin{array}{c}\text { Dist water + } \\
\text { Acetic acid (ml) }\end{array}$ & - & - & - & - & $15+0.5$ & $15+0.5$ \\
\hline $\begin{array}{c}\text { PEG 400 (\% } \\
\text { W/V) }\end{array}$ & $30 \%$ & $30 \%$ & $30 \%$ & $30 \%$ & $30 \%$ & $30 \%$ \\
\hline
\end{tabular}

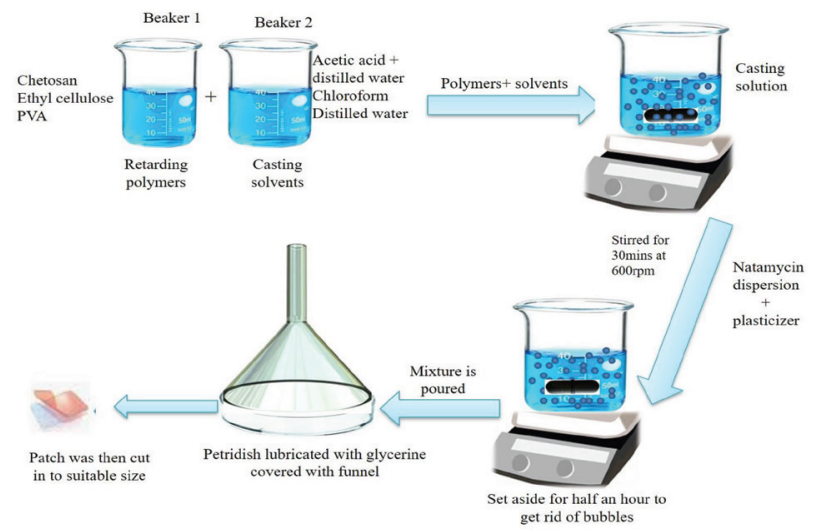

Figure 1: Representation of method of preparation of Natamycin ophthalmic films by solvent casting method.

the Natamycin solid dispersion incorporated films are given in Table 2. The casting solutions were prepared by dissolving the specified concentration of polymers in suitable solvents using a magnetic stirrer for $30 \mathrm{~min}$ to get a uniform dispersion. Natamycin dispersions equivalent to $1.44 \mathrm{gms}$ of drug and plasticizer (30\%) were added during constant stirring $(600 \mathrm{rpm})$ in the polymeric solution. It was then set aside for $1 / 2 \mathrm{hr}$ to get rid of the bubbles. The mixture was poured into a pre-lubrication petridish with glycerin. The petridish was enclosed in an inverted funnel and left untouched overnight for regulated evaporation. The films were carefully removed and cut into $4 \times 2 \mathrm{~mm}$ pieces before being wrapped in butter paper and stored at room temperature. The pictorial representation of the method of preparation of Natamycin ophthalmic films is shown in Figure 1.

\section{Evaluation of Prepared Films}

\section{Physical Appearance and Surface Texture}

The prepared formulations were inspected visually for their appearance, texture, and clarity.

\section{Surface $\mathrm{pH}$}

To swell the film, it was kept in contact with $0.5 \mathrm{ml}$ of neutral water. The electrode was made to come into contact with the ocular film, and the $\mathrm{pH}$ was recorded in triplicates after one minute of equilibration with a $\mathrm{pH}$ meter (Elite Scientific Corporation, Haryana, India). ${ }^{20}$

\section{Thickness of Film}

Using a vernier caliper, the thickness of the film was measured. The film was folded a certain number of times and the measured value was divided by the number of folds. This demonstrates the film's thickness uniformity as well as the polymer's distribution homogeneity. ${ }^{21}$ All measurements were carried out three times.

\section{Uniformity of Weight}

Five films were chosen at random from each batch of the formulation, and their weight was assessed using a digital balance. ${ }^{22}$ The average weight was reported in triplicates.

\section{Folding Endurance}

The film was folded repeatedly in the same spot until it broke at that point. The number of folds required to break the film was calculated..$^{20}$ This was analyzed three times and the average was considered.

\section{Drug Content Uniformity}

All ophthalmic film formulations of $4 \times 2 \mathrm{~mm}$ were dissolved in $7.4 \mathrm{pH}$ phosphate buffer, stirred for $1 \mathrm{hr}$ on a magnetic stirrer, filtered and filtrate was analyzed for drug content at $303 \mathrm{~nm}$ by UV-spectrophotometer. For all the formulations, triplicate study was performed. ${ }^{23}$

\section{Tensile Strength}

The $3 \times 4 \mathrm{~cm}$ ophthalmic film was clamped between two clamps spaced $3 \mathrm{~cm}$ apart. The tensile strength of the film was determined by adding weights to the pan until the film broke. The total weight was recorded, and the tensile strength was calculated in triplicate. ${ }^{20}$ Using, following formula.

Tensile strength $\mathrm{g} /(\mathrm{cm})^{2}=($ Load at failure $(\mathrm{g}) \mathrm{X} 100) /$ (Cross sectional area $\left((\mathrm{cm})^{2}\right)$ )

\section{Percent Moisture Absorption}

It is one of the ways of checking the physical stability of the ophthalmic film under high humidity conditions. 
The prepared ophthalmic films were weighed and stored for three days in the desiccator. As a desiccant, aluminium chloride solution is employed (79.5 percent humidity). ${ }^{20}$ All ophthalmic films were weighed, and moisture absorption percentages were estimated using the formula, in triplicate.

Percent moisture absorption $=($ Final weight-Initial weight $) /($ Final weight) X 100

\section{Percent Moisture Loss}

Anhydrous calcium chloride is present in the dissector. The films were weighed and stored for three days. The moisture loss was determined using the following equation after the films were re-weighed. ${ }^{23}$

Percent moisture loss $=($ Initial weight-final weight $)$ / Initial weight $\times 100$

\section{In-vitro Diffusion Study}

The Franz diffusion cell was used to determine the in-vitro drug release profile of ophthalmic films. The donor compartment contained the $8 \mathrm{~mm}$ films, while the receptor compartment held the simulated tear solution. The dialysis membrane (molecular weight cutoff of 12,000-14,000 Dalton) was fixed as a semipermeable membrane between the donor and receptor compartments, with the rpm set to 50 and the temperature set to $37 \pm 1^{\circ} \mathrm{C}$. Samples were withdrawn at a specified interval of up to $8 \mathrm{hr}$. Sink condition was maintained and samples were analyzed at $303 \mathrm{~nm} .{ }^{24}$

\section{In-vitro Transcorneal Permeation Studies}

A local sloutry house provided the goat eye. The core layer was excised and cleaned with saline, which was kept at $4^{\circ} \mathrm{C}$ until it was used. The cornea was rinsed in cold normal saline to remove the protein. The cornea was positioned between the donor and receptor compartments so that the outer epithelial faced the donor compartment. For $8 \mathrm{hr}$, the receptor compartment was filled with simulated tear fluid that was kept at $37^{\circ} \mathrm{C}$ with continual stirring at 50rpm using a Teflon coated magnetic bead. The cornea in the donor compartmentwascovered with $4 \times 2 \mathrm{~mm}$ ophthalmicfilm, and the donor compartment was sealed with a glass cover slip. At specified time interval $1 \mathrm{ml}$ of fluid was withdrawn (from receptor compartment) and replaced with fresh simulated tear fluid to maintain the sink condition. Withdrawn samples were analyzed at $303 \mathrm{~nm}$ for drug content. ${ }^{25}$

\section{Ocular Toxicity Study}

The Draize test was adapted to assess ocular toxicity in accordance with OECD recommendations. The
InstitutionalAnimalEthicalCommittee(IAEC) provided ethical clearance for the management of experimental animals (albino rabbits of either sex) (Resolution No. KLECOP/CPCSEA/Res.No-221/Po/Re/S/2000/ CPCSEA. Reg. 27-24-12-2018). The animals were divided into 3 groups, each group containing 6 rabbits marked as test, control, and placebo groups, respectively. Throughout the experiment, they were kept in an animal housing at room temperature and supplied with standard feed and water. The placebo group received a placebo film, whereas the control group received nothing. The test group received sterile best formulation. The ophthalmic film was placed in the cul-de-sac of the rabbit (test group) once a day for 7 days and corneal irritancy was tested at specific time intervals of $24 \mathrm{hr}, 48 \mathrm{hr}$, $72 \mathrm{hr}$. After 1 week, all the animals were observed for redness, swelling, discharge, hemorrhaging, cloudiness, ulceration and blindness. ${ }^{26}$

\section{Antimicrobial Activity}

A Candida albican media containing Sabouraud dextrose agar was used to test antimicrobial activity in vitro. For inoculation, the streak method was utilized, and the samples were incubated at $35 \pm 4^{\circ} \mathrm{C}$ for $24 \mathrm{hr}$. The autoclave was used to sterilize $60 \mathrm{ml}$ of Sabouraud dextrose agar, which was then placed into the previously sterilized petridish and solidified at room temperature. The fungal suspension was made using sterile saline water, and $1 \mathrm{ml}$ of it was placed into a $9 \mathrm{~cm}$ diameter petridish and incubated at $35 \pm 4^{\circ} \mathrm{C}$ temperature. Wells $(8 \mathrm{~mm})$ were made using cork bores. In three petridishes, $4 \times 2 \mathrm{~mm}$ $(30 \mathrm{mg})$ optimized ophthalmic film, $0.6 \mathrm{ml}$ of marketed suspension $(5 \%)$, and $4 \times 2 \mathrm{~mm}$ placebo ophthalmic films were introduced respectively, in the aseptic condition. All petridishes were incubated at $35 \pm 4^{\circ} \mathrm{C}$ for $24 \mathrm{~h}$. Zone of inhibition was measured after $24 \mathrm{hr} .^{27}$

\section{Kinetic Modeling of the Drug Release}

The cumulative amount of drug permeated per square centimeter of all the ophthalmic film was fitted into zero order, first order, Higuchi kinetic model, and Korsmeyer peppas models, to calculate the release constant and regression coefficients $\left(\mathrm{R}^{2}\right)$ using PCP DISSO V3 software.

\section{Stability Studies}

Stability testing provides information on the shelf-life of drugs or dosage forms and their recommended storage conditions. The stability study of NF6 formulation was carried out at normal condition $25 \pm 2^{\circ} \mathrm{C}$ and $\mathrm{RH}$ $60 \pm 5 \%$ and accelerated condition at $40 \pm 2^{\circ} \mathrm{C}$ and 75 
$\mathrm{RH} \pm 5 \%$ in stability chamber for a period of 90 days. Films were wrapped in a butter paper followed by aluminium foil and placed in an aluminium pouch. They were evaluated for drug content, tensile strength and in-vitro diffusion studies after storage of 15days, 30days, 60 days and 90 days.

\section{RESULTS AND DISCUSSION}

\section{Solubility Studies}

The maximum solubility of Natamycin was $5 \mathrm{mg} / \mathrm{ml}$ in a mixture of ethanol and acidic buffer $(\mathrm{pH}$ 6.8) in 1:2 ratio. It is practically insoluble in water and $0.05 \mathrm{mg} / \mathrm{ml}$ was soluble in methanol.

\section{Evaluation of Solid Dispersions}

The solid dispersion was prepared by utilizing three polymers: HPMC K100M, HPMC K4M, and PVA in 1:1, 1:2, and 1:3 ratios, respectively. The drug release was investigated for each polymer ratio. In comparison to different polymers and their ratios, it was discovered that drug: HPMC K4M in a 1:3 (SD-6) ratio had the maximum drug release. The HPMC K4M solid dispersed product was further utilized for film formulation. Table 3 shows the drug content and percent drug release of all solid dispersions.

\begin{tabular}{|c|c|c|}
\hline \multicolumn{3}{|c|}{ Table 3: Evaluation of Natamycin Solid Dispersed } \\
Products. \\
\hline Formulation code & $\%$ Drug content & $\begin{array}{c}\text { \% Drug release } \\
\text { at } 60 \text { mins }\end{array}$ \\
\hline SD1 & $95.67 \pm 1.8$ & $74.93 \pm 3.4$ \\
\hline SD2 & $96.23 \pm 2.1$ & $83.84 \pm 2.7$ \\
\hline SD3 & $94.38 \pm 0.9$ & $93.52 \pm 2.8$ \\
\hline SD4 & $92.64 \pm 2.2$ & $82.14 \pm 3.5$ \\
\hline SD5 & $95.87 \pm 1.5$ & $90.67 \pm 3.2$ \\
\hline SD6 & $98.22 \pm 2.4$ & $95.11 \pm 4.1$ \\
\hline SD7 & $96.09 \pm 1.6$ & $61.32 \pm 2.6$ \\
\hline SD8 & $93.76 \pm 1.8$ & $57.45 \pm 3.2$ \\
\hline SD9 & $98.22 \pm 0.8$ & $69.03 \pm 1.2$ \\
\hline
\end{tabular}

\section{Evaluation of Natamycin Ophthalmic Films}

\section{Physical Appearance, Surface Texture and $\mathrm{pH}$ of Ophthalmic Films}

All the formulations prepared (NF1-NF6) were clear and elegant in appearance and the films had a smooth surface without any cracks and imperfections. The film's acidity and alkalinity are determined by the $\mathrm{pH}$ of the film's surface. The $\mathrm{pH}$ of the ocular fluid ranges from 6.8 to 7.5. The film's varied alkalinity may cause irritation or harm to the eye. The surface $\mathrm{pH}$ of the formulation NF1-NF6 was in the acceptable range of 6.8-7.2 $\mathrm{pH}$ indicating films have less potential to irritate eyes and are highly acceptable by patients. All prepared films possess a surface $\mathrm{pH}$ which was compatible with simulated tear fluid of $\mathrm{pH}$ 7.4. (Table 4).

\section{Thickness, Weight Variation and Folding Endurance}

The thickness of the formulations NF1-NF6 was in the range of $0.0245 \pm 0.38 \mathrm{~mm}-0.07031 \pm 0.75 \mathrm{~mm}$. These findings revealed that the polymer and drug were distributed uniformly. The average weight of all formulations NF1-NF6 was in the range of $126 \pm$ $1.252 \mathrm{mg}$ to $129 \pm 2.02 \mathrm{mg}$ which was within the acceptable limit. The folding endurance reflects the mechanical strength of the film and for (NF1-NF6) formulations it was in the range of 260-453 (Table 4).

\section{Drug Content and Tensile Strength}

The goal of determining drug content is to ensure that the drug is distributed evenly throughout the film. Formulations NF1-NF6 showed drug content in the range of $95.30 \%$ to $98.28 \%$. Tensile strength of the formulations NF1-NF6 were in the range of $29 \pm 0.812$ $45 \pm 0.8779$ and was in an acceptable range (Table 5). It was observed that, as the concentration of the plasticizer increased, gradually there was an increase in the folding endurance and tensile strength, the films of all the formulations NF1 to NF6 had good mechanical strength, flexibility and elasticity at the particular concentration of polymer.

\begin{tabular}{|c|c|c|c|c|c|}
\hline \multicolumn{6}{|c|}{ Table 4: Evaluation of Natamycin Solid Dispersion Incorporated Ophthalmic Films. } \\
\hline Formulation Code & Surface Texture & Surface pH & Thickness(mm) & Weight $(\mathbf{m g})$ & Folding Endurance \\
\hline NF1 & Smooth & $7.1 \pm 0.241$ & $0.024 \pm 0.38$ & $126 \pm 1.252$ & $260 \pm 0.451$ \\
\hline NF2 & Smooth & $6.8 \pm 0.152$ & $0.070 \pm 0.75$ & $128 \pm 2.516$ & $453 \pm 1.732$ \\
\hline NF3 & Smooth & $7.3 \pm 0.115$ & $0.063 \pm 0.10$ & $126 \pm 2.081$ & $350 \pm 0.577$ \\
\hline NF4 & Smooth & $7.0 \pm 0.192$ & $0.043 \pm 0.25$ & $127 \pm 1.244$ & $345 \pm 1.254$ \\
\hline NF5 & Smooth & $7.2 \pm 0.210$ & $0.070 \pm 0.75$ & $129 \pm 2.025$ & $280 \pm 1.356$ \\
\hline NF6 & Smooth & $7.2 \pm 0.120$ & $0.035 \pm 0.42$ & $127 \pm 1.527$ & $311 \pm 2.645$ \\
\hline
\end{tabular}


Table 5: Evaluation of Solid Dispersion Incorporated Ophthalmic Films.

\begin{tabular}{|c|c|c|c|c|}
\hline Formulation code & $\begin{array}{c}\text { Tensile strength } \\
\left(\mathbf{g} / \mathbf{c m}^{2}\right) \mathbf{~ S D}\end{array}$ & $\begin{array}{c}\text { Drug content } \\
(\mathbf{\%}) \pm \mathbf{S D}\end{array}$ & $\begin{array}{c}\text { Moisture Absorption } \\
(\%) \pm \text { SD }\end{array}$ & $\begin{array}{c}\text { Moisture Loss } \\
(\%) \pm \text { SD }\end{array}$ \\
\hline NF1 & $35.0 \pm 0.76$ & $96.82 \pm 0.28$ & $2.75 \pm 0.34$ & $3.82 \pm 0.42$ \\
\hline NF2 & $45.0 \pm 0.87$ & $97.27 \pm 0.41$ & $2.92 \pm 0.44$ & $3.70 \pm 0.39$ \\
\hline NF3 & $42.5 \pm 0.62$ & $95.30 \pm 0.38$ & $3.26 \pm 0.38$ & $3.11 \pm 0.05$ \\
\hline NF4 & $32.0 \pm 0.81$ & $98.28 \pm 0.47$ & $3.86 \pm 0.24$ & $3.67 \pm 0.24$ \\
\hline NF5 & $30.4 \pm 0.12$ & $95.74 \pm 0.41$ & $3.96 \pm 0.42$ & $3.55 \pm 0.27$ \\
\hline NF6 & $31.2 \pm 1.22$ & $96.20 \pm 0.46$ & $3.58 \pm 0.39$ & $2.38 \pm 0.76$ \\
\hline
\end{tabular}

\section{Moisture Absorption and Moisture Loss}

The moisture absorption and moisture loss of all formulations were depicted in Table 5 and were found in the range of $2.752 \pm 0.348$ to $3.96 \pm 0.422$ and $2.387 \pm 0.768$ to $3.821 \pm 0.421$ respectively, and were in an acceptable range.

\section{In-vitro Permeation Studies}

In-vitro permeation study for NF1, NF2, NF3, NF4, NF5 and NF6 showed the release of $79.48 \%, 90.63 \%$, $85.147 \%, 85.72 \%, 82.81 \%$ and $80.21 \%$ respectively. Based on the in-vitro study NF1, NF3 and NF5 showed faster and complete release in 4 to $5 \mathrm{hr}$ and thus were rejected. The use of retarding polymers in the formulation (PVA, Ethyl cellulose and Chitosan) successfully contributed to the sustained release of the drug and in-vitro permeability of NF2, NF4 and NF6 for $8 \mathrm{hr}$ was found to be in the range of $90.63 \%, 85.14 \%$ and $80.21 \%$ respectively. On the basis of the overall evaluation parameter, NF6 was determined to be the best of the three formulations.

The decreased drug release at higher concentrations of PVA (NF1 and NF2) and chitosan (NF5 and NF6) was may be due to their tendency to form an intense and denser molecular network. Ethyl cellulose (EC) is the most utilized polymer in the preparation of sustained drug delivery systems because it's biocompatible, versatile and lower cost. ${ }^{28}$ As the EC concentration ratio increased from $0.25 \mathrm{gm} 0.30 \mathrm{gm}$, (NF3 and NF4) the in vitro drug release decreased, refer to Figure 2. The reason for this could be longer diffusion pathway of the drug in the higher ratio, so the release was retarded. This agrees with Yadav et al. ${ }^{29}$

\section{Ex-vivo Permeation Studies}

Ex-vivo permeation study was conducted using the cornea of a goat and at the end of 8 hrs percentage cumulative drug permeation of optimized formulation NF6 was found to be $76.30 \%$. The permeation of NF6 by in-vitro was $80.21 \%$ and by ex-vivo was $76.30 \%$.

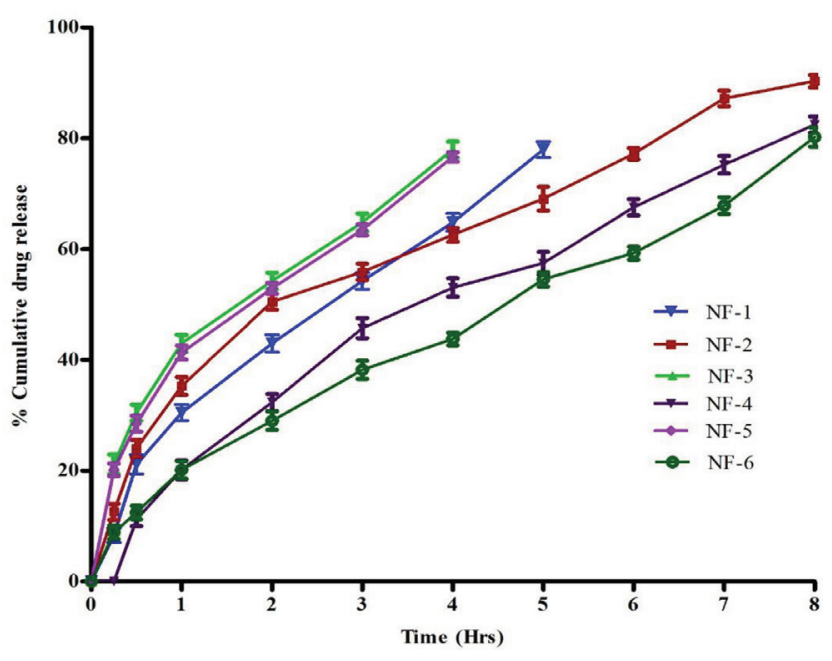

Figure 2: In-vitro release profile of all Natamycin ophthalmic films.

The drug permeation was high in the in-vitro studies as compared to ex-vivo. This is due to the fact that the, real cornea is a semipermeable membrane with varying pore size and also some other fatty tissues hinder the permeation of drugs through the cornea. Also, the cornea is made up of the epithelium (lipophilic), stroma (hydrophilic) and endothelium (less lipophilic than epithelium) which act as a lipophilic-hydrophilic barrier for corneal penetration, while the dialysis membrane acts as a mechanical barrier. ${ }^{21}$ The in vitro release profile of all formulations (NF1-NF6) is depicted in Figure 2 and the comparative in vitro-ex vivo release of the optimized formulation is shown in Figure 3.

\section{Antimicrobial Activity Using Cup-let Method}

The zone of inhibition observed (24hr) for optimized NF-6 film was $9.5 \mathrm{~mm}$ and for the marketed formulation was $10 \mathrm{~mm}$ and for placebo it was $3 \mathrm{~mm}$ as shown in Figure 4. The results of the optimised formulation were satisfactory. Chitosan is an antibacterial agent itself, according to a placebo report. After 10-15 days of incubation at $35^{\circ} \mathrm{C} \pm 4^{\circ} \mathrm{C}$, the ophthalmic film was released in a controlled manner. According to the 




Figure 3: Comparative in-vitro and ex vivo drug release profile of optimized formulation NF-6.
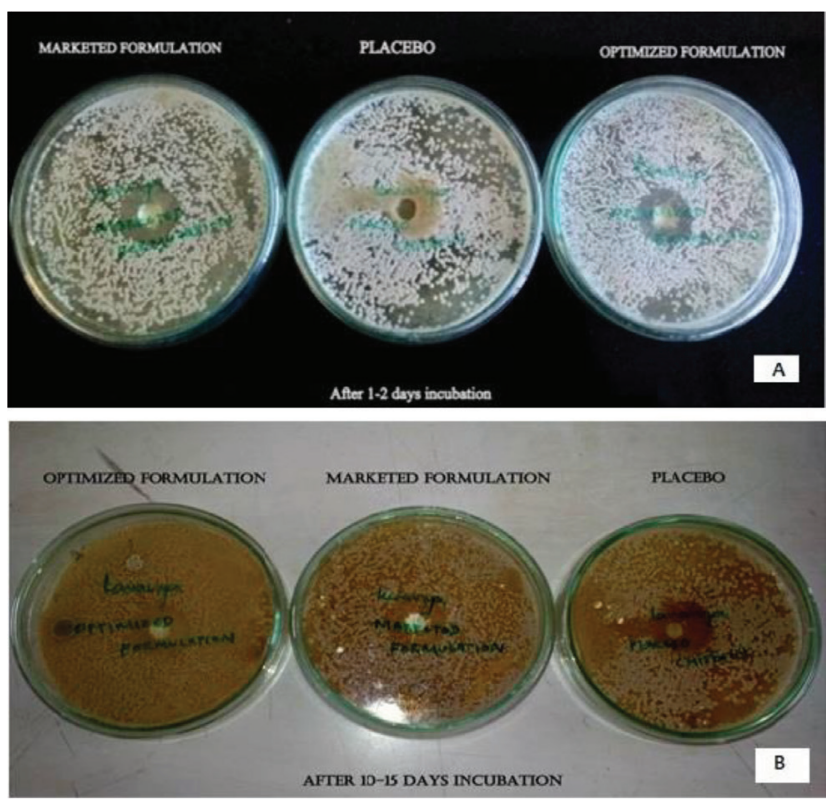

Figure 4: In-vitro antifungal activity (zone of inhibition) of optimized formulation NF-6 against strain Candida albicans.

findings, there was no microbial development in the inhibited area. In-vitro anti-microbial tests showed that the zone of inhibition was sustained for $24 \mathrm{hr}$, and the same zone size was maintained for upto 15 days.

The eye irritation score from individual rabbits was added to get the total irritation score that was subsequently divided by the total number of rabbits used for the ocular irritancy test to obtain the final eye irritation score. The calculated eye irritation score was 0.23 in control while for NF6 it was 0.47 , which demonstrates good ocular tolerance. All the rabbits were kept under observation for $24 \mathrm{hr}$. There was no irritation, inflammation, and redness found in the placebo with


Figure 5: Results of ocular irritation study A-Placebo film administered rabbit eye, B -Control group rabbit eye and C-Optimized film NF-6 administered rabbit eye.

respect tooptimized formulationNF6 and controleye. The ocular irritation test revealed that prepared formulation was non-irritant for ocular administration (Figure 5).

\section{Kinetic Modeling of the Drug Release}

To obtain the release constant and regression coefficients (R2), the release data was fitted into various kinetic models. The drug release profile for all formulations NF1 to NF6 revealed Higuchi kinetics among the models studied. The diffusion mechanism was responsible for the release profiles. All of the formulations (NF1-NF6) had a diffusion exponent ( $\mathrm{n}$ ) of less than 0.5 , indicating a Fickian mechanism of drug release.

\section{Short-term Stability Studies}

The stability study of the optimized formulations for 90 days revealed that the formulations were stable at room temperature as well as in the accelerated stability conditions as there was no significant difference in drug content, tensile strength, and in-vitro diffusion studies after storage for 90 days, which confirms the potentiality of the films for longer storage.

\section{CONCLUSION}

This study evaluated the suitability and feasibility of delivering Natamycin in the form of an ophthalmic film through the ocular route with the goal of avoiding the loss of the drug, an increase in the retention time of the drug and preventing the frequent dosing, along with enhancement in the rate of drug release, diffusion, and better patient compliance. Ophthalmic films were successfully prepared by using polymers (PVA, Ethyl cellulose, and Chitosan) by the solvent casting method. It was observed that as the concentration of the plasticizer increased, gradually there was an increase in the folding endurance and tensile strength. The films of all the formulations NF1 to NF6 had with good mechanical strength, no deviation in weight, and good folding endurance. The optimized formulation NF6 shows more drug release in in-vitro studies as compared to ex-vivo. This is due to the varying pore size of the cornea 
and disturbance of other tissues. An ocular irritation test revealed that the prepared formulation was nonirritant. Thus, the formulated ophthalmic film seems to be a promising formulation for the safe and effective delivery of Natamycin through the ocular route in treatment of fungal keratitis.

\section{ACKNOWLEDGEMENT}

Authors are thankful to Chihong biotechnology china, for providing Natamycin as a gift sample for our research work. Authors are also thankful to the KLE Academy of Higher Education Research, Belagavi and Dr. Prabhakar Kore Basic Science Research Centre, KLE Academy of Higher Education Research, Belagavi for providing fasilities to carry out the work.

\section{CONFLICT OF INTEREST}

The authors declare no conflict of interest.

\section{ABBREVIATIONS}

HPMC: Hydroxypropyl methylcellulose; PVA: Poly (vinyl alcohol); PEG: Poly(ethylene glycol; SD: Solid dispersion; EC: Ethyl cellulose.

\section{REFERENCES}

1. Rajasekaran A, Sivakumar V, Karthika K, Preetha JP, Abirami T. Design and evaluation of polymeric controlled release natamycin ocular inserts. Kathmandu Univ J Sci Eng Technol. 2010;6(1):108-15. doi: 10.3126/kuset. v6i1.3318.

2. Nayak BS, Patnaik SC, Sethy S, Ellaiah P, Sarangi BK. Formulation design and in vitro-in vivo evaluation of moxifloxacin ophthalmic insert. Int $\mathrm{J}$ Med Res. 2015 Apr 13;3(4):302-12.

3. Jeganath $\mathrm{S}, \mathrm{Viji} \mathrm{AA}$, Devi KS. Design and evaluation of controlled release ocuserts of indomethacin. Int J Pharm Sci Res. 2011;2:80-6.

4. Kumar BP, Harish G, Bhowmik D. Ocular inserts: A novel controlled drug delivery system. J Pharm Innov. 2013 Feb 1;1(12):1-16.

5. Roy P, Das S, Singh NP, Saha R, Kajla G, Snehaa K, Gupta VP. Changing trends in fungal and bacterial profile of infectious keratitis at a tertiary care hospital: A six-year study. Clin Epidemiol Glob Health. 2017 Mar 1;5(1):40-5. doi: 10.1016/j.cegh.2016.02.001.

6. Ansari Z, Miller D, Galor A. Current thoughts in fungal keratitis: diagnosis and treatment. Curr Fungal Infect Rep. 2013 Sep 1;7(3):209-18. doi: 10.1007/ s12281-013-0150-110.1007/s12281-013-0150-1, PMID 24040467.

7. Al-Falki YH, Alshehri MA, Joseph MRP, Hamid ME. Fungal keratitis caused by a rare ocular pathogen, Gjaerumia minor: A case report. Saudi J Ophthalmol. 2018 Apr 1;32(2):160-3. doi: 10.1016/j.sjopt.2017.09.007, PMID 29942188.

8. Abdul Ahad H, Sreeramulu J, Padmaja BS, Reddy MN, Prakash PG. Preparation of Fluconazole $\beta$-Cyclodextrin Complex Ocuserts: In Vitro and In Vivo Evaluation. ISRN Pharm. 2011;2011:237501. doi: 10.5402/2011/237501. PMID 22389846.

9. Tofighia P, Soltani S, Montazam SH, Montazam SA, Jelvehgari M. Formulation of tolmetin ocuserts as carriers for ocular drug delivery system. Iran J Pharm Res. 2017;16(2):432-41. PMID 28979298.

10. Gurtler F, Gurny R. Patent literature review of ophthalmic inserts. Drug Dev Ind Pharm. 1995;21(1):1-18. doi: 10.3109/03639049509048094.
11. El-Nabarawi MA, Abd El Rehem RT, Teaima M, Abary M, El-Mofty HM, Khafagy MM, Lotfy NM, Salah M. Natamycin niosomes as a promising ocular nanosized delivery system with ketorolac tromethamine for dual effects for treatment of candida rabbit keratitis; in vitro/in vivo and histopathological studies. Drug Dev Ind Pharm. 2019;45(6):922-36. doi: 10.1080/03639045.2019.1579827, PMID 30744431.

12. Abdelmonem R, El-Nabarawi MA, Attia AM, Teaimaa M. Ocular delivery of natamycin solid lipid nanoparticle loaded mucoadhesive gel: formulation, characterization and in vivo study. Int J Appl Pharm. 2020 Sep 7:173-80.

13. Khames A, Khaleel MA, El-Badawy MF, El-Nezhawy AOH. Natamycin solid lipid nanoparticles - sustained ocular delivery system of higher corneal penetration against deep fungal keratitis: preparation and optimization. Int J Nanomedicine. 2019;14:2515-31. doi: 10.2147/IJN.S190502, PMID 31040672.

14. Lorenzo-Veiga B, Sigurdsson HH, Loftsson T, Alvarez-Lorenzo C. Cyclodextrin-Amphiphilic Copolymer Supramolecular Assemblies for the Ocular Delivery of Natamycin. Nanomaterials (Basel). 2019 May;9(5):745. doi: 10.3390/nano9050745, PMID 31096569.

15. Suharyani I, Pamudji JS, Wikarsa S, Kurniati NF. Natamycin nanosuspension for ophthalmic drug delivery system. Res J Pharm Biol Chem Sci. 2017 Jan 1;8:113-20.

16. Gurtler F, Kaltsatos V, Boisramé B, Gurny R. Long-acting soluble bioadhesiveophthalmic drug insert (BODI) containing gentamicin for veterinary use: optimization and clinical investigation. J Control Release. 1995;33(2):231-36. doi: 10.1016/0168-3659(94)00096-D.

17. Singh J, Walia M, Harikumar SL. Solubility enhancement by solid dispersion method: a review. J Drug Delivery Ther. 2013 Sep 14;3(5):148-55. doi: 10.22270/jddt.v3i5.632.

18. Sapkal SB, Shinde SA, Darakhe RA, Shrikhande VN. Solid dispersion of valsartan for solubility improvement using $\beta$-cyclodextrin. MOJ Bioequiv Availab. 2018;5(6):313-9.

19. Amar A. Formulation and evaluation of controlled release ocular inserts of betaxolol hydrochloride. iosrphr. 2012;2(5):34-8. doi: 10.9790/3013-25203438.

20. Priya KN, Bhattacharyya S, Babu PR. Formulation and evaluation of erodible ocular films of valacyclovir hydrochloride. Dhaka Univ J Pharm Sci. 2014;13(1):75-81. doi: 10.3329/dujps.v13i1.21866.

21. Rao PC, Nappinnai M, Raju S, Rao UM, Reddy VB. Fluconazole ocular inserts: formulation and in-vitro evaluation. Int J Pharm Sci Res. 2010 Jun 1;2(6):344.

22. Patel M, Patel M, Patel D. Formulation and evaluation of drug-free ophthalmic films prepared by using various synthetic polymers. J Young Pharmacists. 2009 Apr 1;1(2):116. doi: 10.4103/0975-1483.55742.

23. Ghelani TK, Seth AK, Saini V, Singhal S, Kumar S, Yadav YC. Formulation and evaluation of timolol maleate ocular insert. Asian J Biochem Pharm Res. 2011;1(1):166-74.

24. Nayak BS, Patnaik SC, Sethy S, Ellaiah P, Sarangi BK. Formulation design and in vitro-in vivo evaluation of moxifloxacin ophthalmic insert. Int. Med Res Rev. 2015 Apr 13;3(4):302-12.

25. Dave V, Paliwal S, Yadav S. Formulation and evaluation of controlled delivery of aceclofenac through ocular insert. Turk J Pharm Sci. 2013 May 1;10(2):205-20.

26. Gadad AP, Wadklar PD, Dandghi P, Patil A. Thermosensitive in situ gel for ocular delivery of Iomefloxacin. Indian J Pharm Educ Res. 2016 Apr 1;50(2):S96-105.

27. Magaldi S, Mata-Essayag S, Hartung de Capriles $\mathrm{CH}$, Perez C, Colella MT, Olaizola C, Ontiveros $\mathrm{Y}$. Well diffusion for antifungal susceptibility testing. Int J Infect Dis. 2004 Jan 1;8(1):39-45. doi: 10.1016/j.ijid.2003.03.002, PMID 14690779.

28. Aboueisha YA, Gad S, Khalil WF, Ahmed EA, Ghorab MM. Effect of ethyl cellulose content on release profile and pharmacodynamics of fenoprofen microparticles. Indian J Pharm Educ Res. 2019;53(3):446-56. doi: 10.5530/ ijper.53.3.77.

29. Yadav AV, Shete AS, Dabke AP, Shinde VR. Formulation and in-vitro evaluation of aceclofenac microcapsules. Int J Pharm Technol Research. $2009 ; 1(2): 135-8$. 
PICTORIAL ABSTRACT

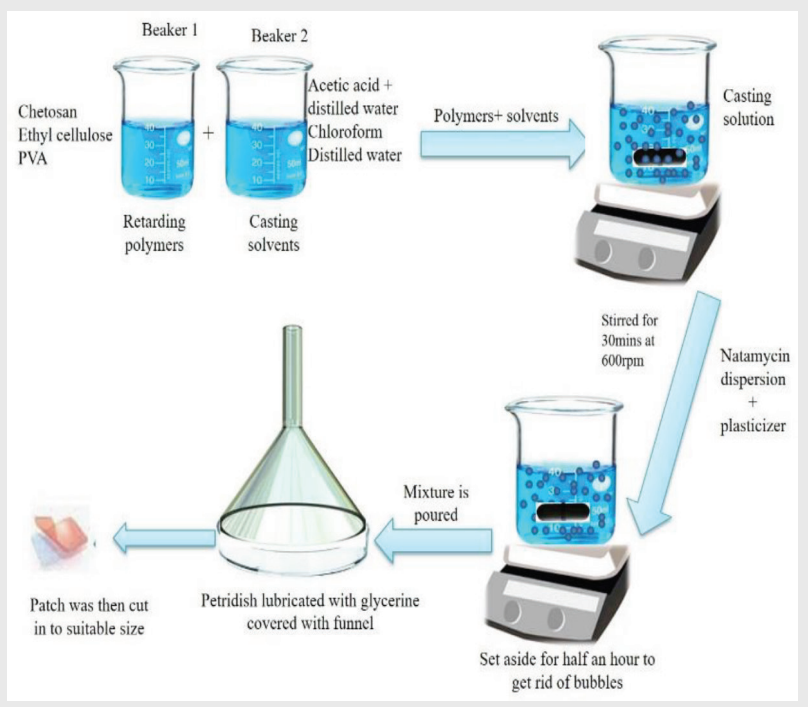

About Authors
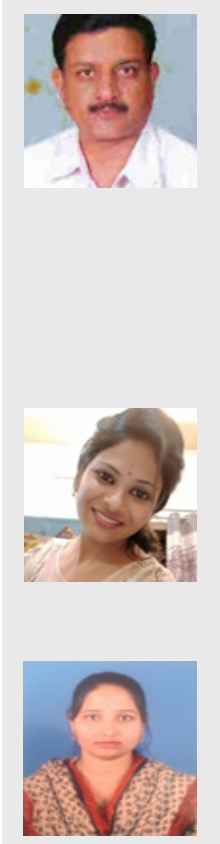

Uday Baburao Bolmal is an Assistant Professor KLE College of Pharmacy, K.L.E Academy of Higher Education and Research, Belagavi. He is working on areas of targeted drug delivery Devices to treat cancer, Design and Development of different models to study the pharmacokinetic studies. Formulation of herbal dental solutions and suspensions and many more.

Lavanya Bhandari is a research scholar, Department of Pharmaceutics, KLE College of Pharmacy, K.L.E Academy of Higher Education and Research, Belagavi. She is working on areas of ophthalmic drug delivery.

Archana S. Patil is an Assistant Professor, Department of pharmaceutics, KLE College of Pharmacy, K.L.E Academy of Higher Education and Research, Belagavi. She is working in the area of targeted drug delivery systems viz, $\mathrm{pH}$ and temperature responsive copolymeric nanoparticles, pulsatile drug delivery systems as well as synthesis and characterization of graft co-polymers for intelligent drug delivery, ophthalmic drug delivery systems etc.

\section{SUMMARY}

- Natamycin belongs to BCS Class II and currently available Natamycin formulation is conventional suspension with doses of $5 \mathrm{mg}$, and has several disadvantages, such as drug loss during the administration and frequent dosing. This leads to greater variability in response.

- In this present study, an attempt was made to formulate sustained release formulation of Natamycin ophthalmic films to avoid the loss of dose and frequent dosing, increase retention time and patient compliance.

- The Natamycin solid dispersions were and based on percent drug release profile SD-6 formulation is selected to incorporate in to ophthalmic films which were prepared by solvent casting method with PFG 400 as plasticizer.

- Further, the formulations were subjected to various evaluation parameters viz. surface $\mathrm{pH}$, drug content, weight uniformity, thickness, folding endurance, tensile strength, in-vitro and ex-vivo permeation studies.

- The films of all the formulations NF1 to NF6 were with good mechanical strength, no deviation in weight, and good folding endurance. The optimized formulation NF6 shows more drug release in the in-vitro studies as compared to ex-vivo.

- Stability study of the optimized formulations for 90 days revealed that the formulations were stable at room temperature as well as in the accelerated stability conditions which confirms the potential of the films for longer storage.

- Thus, it was concluded that the formulated ophthalmic films seem to be a promising formulation for the safe and effective delivery of Natamycin through ocular route in treatment of ocular fungal keratitis.

Cite this article: Bhandari L, Patil AS, Bolmal U, Masareddy R, Dandagi P. Formulation and Evaluation of Natamycin Solid Dispersion Incorporated Ophthalmic Films. Indian J of Pharmaceutical Education and Research. 2022;56(1):103-11. 